\title{
A 3D VirTUAL SimUlation SYSTEM FOR Mobile HaRbour Crane
}

\author{
PARK, H. S. \& LE, N. T.
}

Abstract: Since the simulation technology on computer has emerged as a phenomenon, simulating the real behaviour of a complex mechatronic system without using traditional build-and-test method is an essential approach to the design phase. This paper introduces a novel solution for dynamic modeling and controlling a mobile harbour crane that works in unstable condition on the sea wave. This approach utilizes a complex virtual prototype platform, which integrates three specific software for performing a 3D solid model using SOLIDWORK, modeling the mechanical model using ADAMS, and controlling the mechanical system using MATLAB. From concept of the MHC system, a virtual dynamic model of the MHC mechanical system was developed and simulated in the ADAMS environment to investigate its dynamic behaviour. A controller was then designed in MATLAB/Simulink to control the accuracy of the crane position and suppress the swing angle of the load. The simulation result showed that the reliability and effectiveness of the proposed approach for designing the mechatronic systems.

Key words: virtual prototype, mobile harbour crane, modelling and controlling
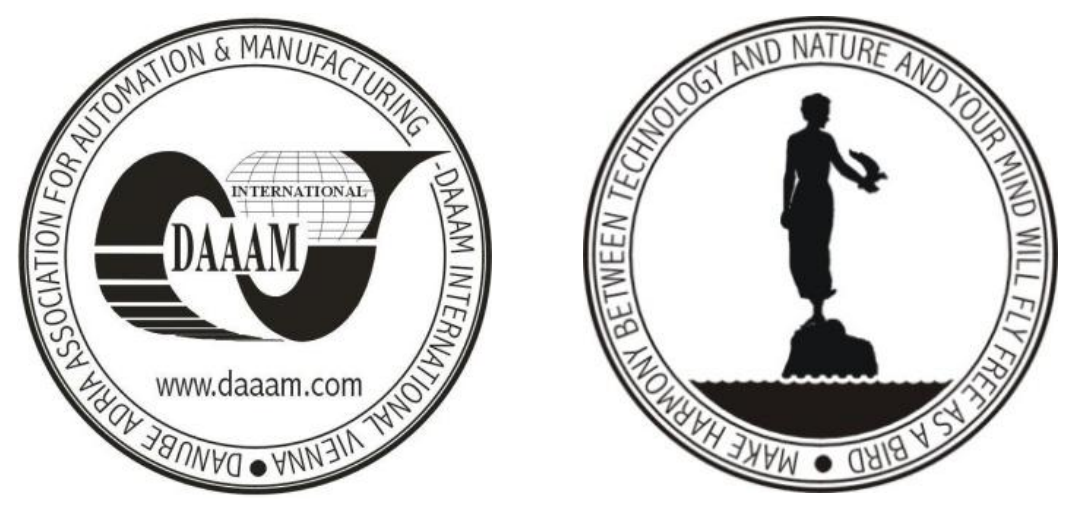

Authors' data: Univ. Prof. Dr.-Ing. Park, H[ong] S[eok]; Ms. Sc. Le, N[goc] T[ran], University of Ulsan, San 29, Mugeo 2-Dong, Nam-Gu, Ulsan 680-749, South Korea, phosk@ulsan.ac.kr, lengoctran@mail.ulsan.ac.kr

This Publication has to be referred as: Park, H[ong] S[eok] \& Le, N[goc] T[ran] (2012). A 3D Virtual Simulation System for Mobile Harbour Crane, Chapter 34 in DAAAM International Scientific Book 2012, pp. 401-412, B. Katalinic (Ed.), Published by DAAAM International, ISBN 978-3-901509-86-5, ISSN 1726-9687, Vienna, Austria

DOI: $10.2507 /$ daaam.scibook.2012.34 
Park, H. S. \& Le, N. T.: A 3D Virtual Simulation System for Mobile Harbour Crane

\section{Introduction}

Since the marine transport of goods has grown, the concept of mobile harbour crane (MHC) was proposed aiming to transport amount of goods from the large container ship that hardly anchors in the shallow water port to their destination. The MHC is an overhead crane system that is mounted in a mobile harbour floating to load and unload the containers from the container ship to its vessels and vice versa. These containers then deliver to the destination ports irrespective of the depth or narrow areas of ports. Due to working on the sea, the MHC system has more problems than conventional crane that is fixed on the ground. One of the main problems is the swing of containers due to continuous movement of the floating base under sea wave force.

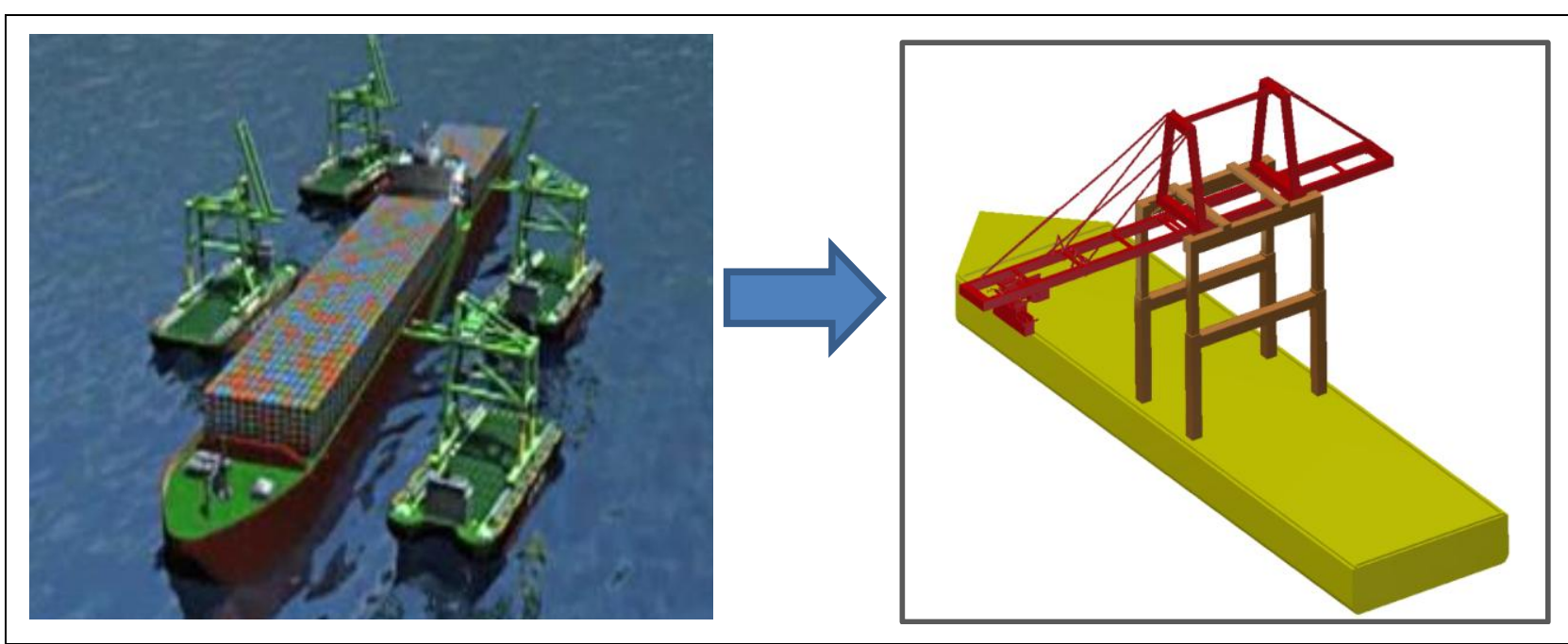

(a)

(b)

Fig.1. Moble harbour crane system: a) concept, b) modeling

According to the many previous researchers for the overhead crane, the sway of the suspended load is caused by improper operator's control of the trolley and disturbance on the load. This sway is a serious problem because it could cause damage to the surround devices and systems. In this case, the disturbance on load (e.g. wind, collision with an object, etc.) is trivial influence to sway motion of load, and it can be predicted and disposed by an experience operator (Kim et al., 2001). However, it is difficult to suppress the swing of load in the situation of MHC system that works in the harsh condition of the sea wave. Because of when the trolley is acceleration or deceleration, the suspended load is swayed by inertia force like the pendulum motion. In addition, the continuous movement of floating base due to wind and wave, this makes the load's trajectory unpredictable. Therefore, controlling the load to a desired position exactly without sway motion is a challenge to resolve.

There are several researchers to reduce the swing for payload of overhead crane. Hong et al. (Hong et al., 2003) proposed an open-loop scheme, which was not equipped with sensors. An appropriate trajectory for the trolley movement has been done to compensate the swing caused by the trolley's movement. This method is economical and stable with the cranes that have a natural frequency, which only 
depends on the length of cable with constant gravity. However, it is unfeasible with unstable plans. In recent years, many studies addressed the feedback control schemes, which are equipped with many types of sensors to detect the swing angle of the load in linear/nonlinear controls. Several measured devices to determine the swing angle of the load were proposed such as a 3D camera (Kawai et al., 2009), inclinometer (Park et al., 2007), and accelerometer (Yoshida et al., 2008). These devices achieve the precision and fast response time. Nevertheless, they are expensive and high cost of maintenance.

In order to test and verify the proposed approach for the mechatronic systems based on the traditional build-and-test method has taken much time and high investment. This paper introduces the virtual simulation technology that integrates a multi-software solution such as SOLIDWORKS, ADAMS, and MATLAB/Simulink. The SOLIDWORKS is used to create a virtual mechanical model with multi-rigid body. The ADAMS is employed to develop a virtual dynamic model with the possibility of virtual measurement of any parameters of any components in the virtual model. MATLAB software is well-known for designing a control system. This cosimulation model has a merit in simulating real behaviour of the mechanical system, and implementing the closed-loop control of the whole virtual prototype model. The simulations of results not help designers to modify mechanical design but also improve the control method.

\section{The MHC system modelling}

The MHC is the overhead crane system that mounted on the floating base. It involves a floating base, frame system, support frame, trolley, spreader and boom. Its model is shown in Fig.2.

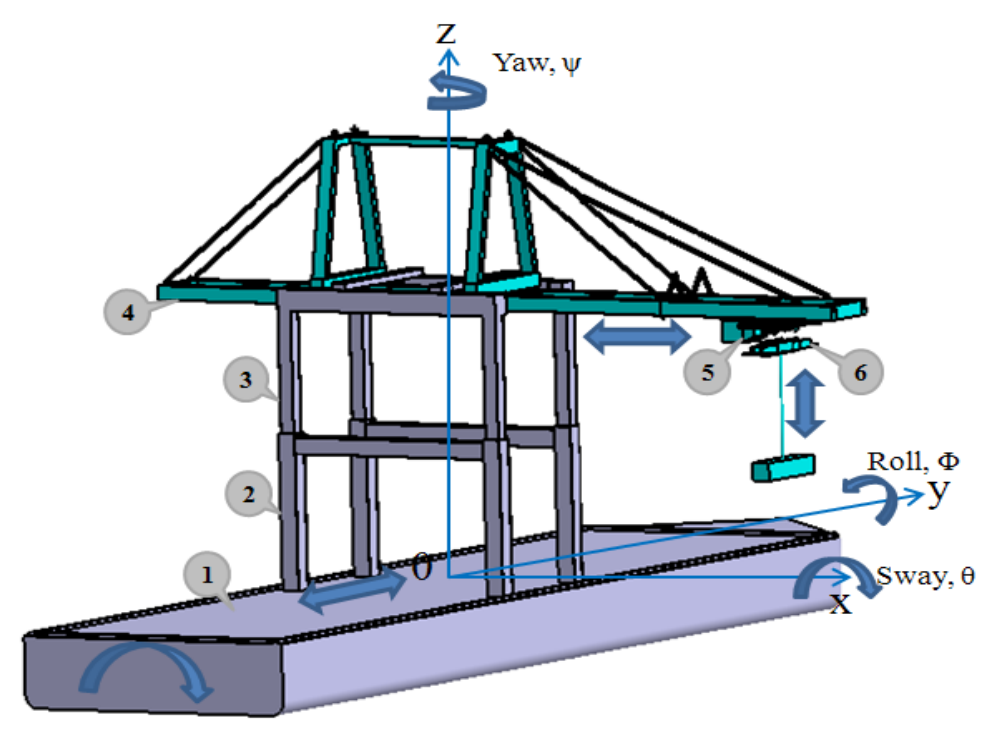

Fig.2. The MHC modeling

1. Floating; 2. Frame; 3. Support frame; 4. Boom; 5. Trolley; 6. Spreader 
The floating carries whole crane system and the loads. It is operated in the sea condition and is swayed by the wave disturbance. The frame system has a steady structure to stand total payload of the crane system. This system moves along the floating and can be adjusted horizontal to pick up a container. The support frame is used to raise the crane up/down when the crane begins working or stopping. This function aims to collapse the crane system for convenient travelling. The trolley moves along the boom rail following the X-direction, and it is driven by a motor force. The spreader is suspended on the trolley by four dynamic cables. It is moved following the trolley's movement. The function of the trolley is to adjust the hooks of a container for lifting.

Because of working under the sea wave condition, the MHC behaviour is affected by wave and wind. According to Spanos (Spanos et al., 1986), the wininduced drap force acting on the crane structures over the seaway can be evaluated based on the fundamental equation of drap force:

$$
F_{D}(t)=\frac{1}{2} \rho C_{D} A \bar{U}^{2}+\rho C_{D} A \bar{U} w(t)+\frac{1}{2} \rho C_{D} A w(t)|w(t)|
$$

where, $\rho$ is air density; $C_{D}$ is drap coefficient; $A$ is projected area of a structure; $\bar{U}$ is a constant wind speed depending on the height above the sea level; the $w(t)$ is a randomly fluctuating turbulent wind speed.

The first term of Eq.(1) is the mean drag force, which is constant for a given mean wind speed. The second and the third terms of Eq.(1) are the forces associated with turbulent winds. Due to the projected area and height structures within the MHC system are negligibility. Thus, the wind force influence to the MHC structure is neglected, and it is considered as a Gaussian random disturbance of the control system.

Otherwise, the sea wave is main effect to the sway motion of the floating base. The description of disturbance due to sea wave is necessary for modelling the MHC floating behaviour. According to Spanos, the wave force is expressed by equation:

$$
S_{w}(t)=f_{a} \sin (\Omega t+\Phi)+B \xi
$$

where, $f_{a}, \Omega$, and $\Phi$ are amplitude, frequency, and phase of wave, respectively.

The first term of Eq.(2) is the harmonic component of the force (denoted by $f_{a} \sin (\Omega t+\Phi)$ ), and the second term of Eq.(2) is the random disturbance component (denoted by $B \xi$ ).

Due to the working condition of the MHC is in the sea with the wave disturbance, which induces the MHC to move following six degree of freedom motions, including three translation motions (surge, sway, and heavy) and three rotation motions (roll, pick, and yaw). The six degree of freedom motion is shown in Fig.2.

In order to model the complex mechanical system of the MHC, some of the following assumptions are considered as:

1) The floating body was supposed to be relatively fixed in the Cartesian coordinate. Thus, the drift of the floating and the yaw motion in absolute coordinates can be neglected. 
2) The trolley movement is considered along $X$-direction, and the sway motion of the suspended load, are on the same plane.

3) The sway motions of the suspended load taking place on the other planes can be considered as the disturbances of the control system.

4) The sway motion of load is consider similarly a pendulum motion, and the friction force on the trolley is negligible.

\section{Developing a virtual simulation prototyping model of the MHC}

Once the competition of production has been increased, the demand of the product development cycle times and cost consuming should be reduced. Meantime, the disadvantage of the traditional build-and-test method was spent taken a lot of time to launch a new product. Therefore, in order to improve the mechanical and control designs of the mechatronic system, the simulation technique based on the virtual prototyping model is proposed as a novel approach that significantly reduces manufacturing time and cost compared to the conventional method.

This approach is an integrating software solution that includes modelling a mechanical system, simulating, and visualizing its 3D motion behaviour under real work operating condition, and refining \& optimizing the design (Alexandru et al., 2009). The advantages of the proposed simulation technique are the ability to perform virtual measurement of any parameters and in any components of the mechanical model can be performed conveniently. The systematic engineering to develop the virtual prototype for designing and testing the MHC system is shown in Fig.3.

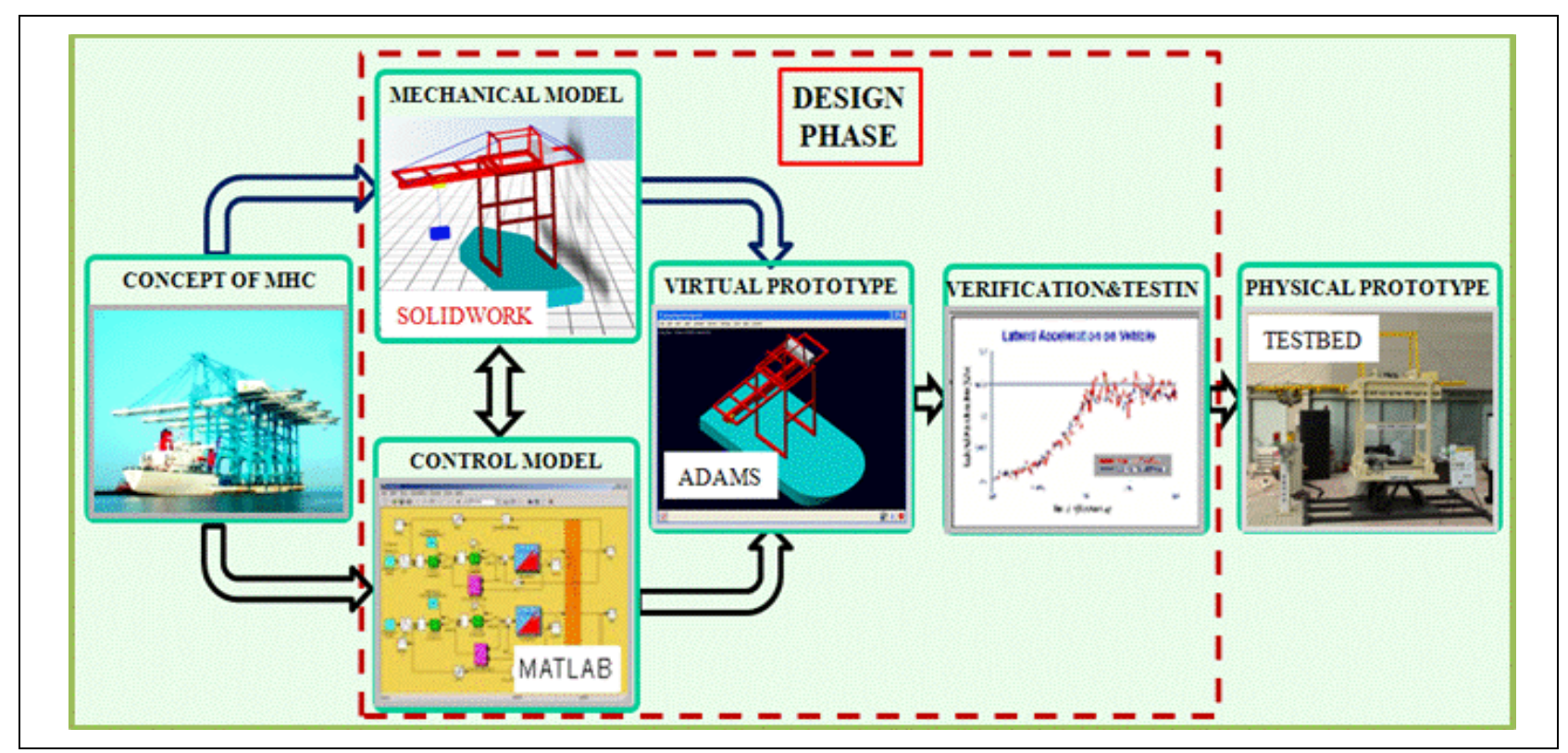

Fig.3. Systematic procedure for develop a virtual prototype of the MHC system

In order to develop the virtual prototype for testing a mechatronic product, based upon the concept of MHC system, firstly, both of mechanical and control designs are made separately with different software tools. After designing step, the separately modules should be tested and verified for satisfying the desired objectives, and finally, a co-test should be implemented on the physical prototype to verify the proposed solution. During testing on the physical prototype, if a problem appears in 
the interaction operation between two systems, the designer must refine the mechanical design and/or control design to obtain an indefectible mechatronic system.

The virtual prototype platform is developed based on the integrated software solution that includes SOLIDWORKS, ADAMS, MATLAB. The SOLIDWORKS software is developed a geometric model, which involves the rigid parts with shape and dimension of the physical model. This geometric model is then exported to ADAMS environment using a file format as Parasolid.x_t. The ADAMS environment is the center component of the virtual prototype platform, which the kinematic and dynamic behaviour of the mechanical system are analyzed, simulated, and optimized under real operating conditions.

In the ADAMS environment, the geometric parameters of the rigid parts such as material, mass, and density must be firstly defined, and then mass and inertial matrices are generated automatically. These parts are connected one with other, respectively to the floating base coordinate using the geometric constraints. The geometric constraint for virtual prototype MHC model is shown in Fig.4.

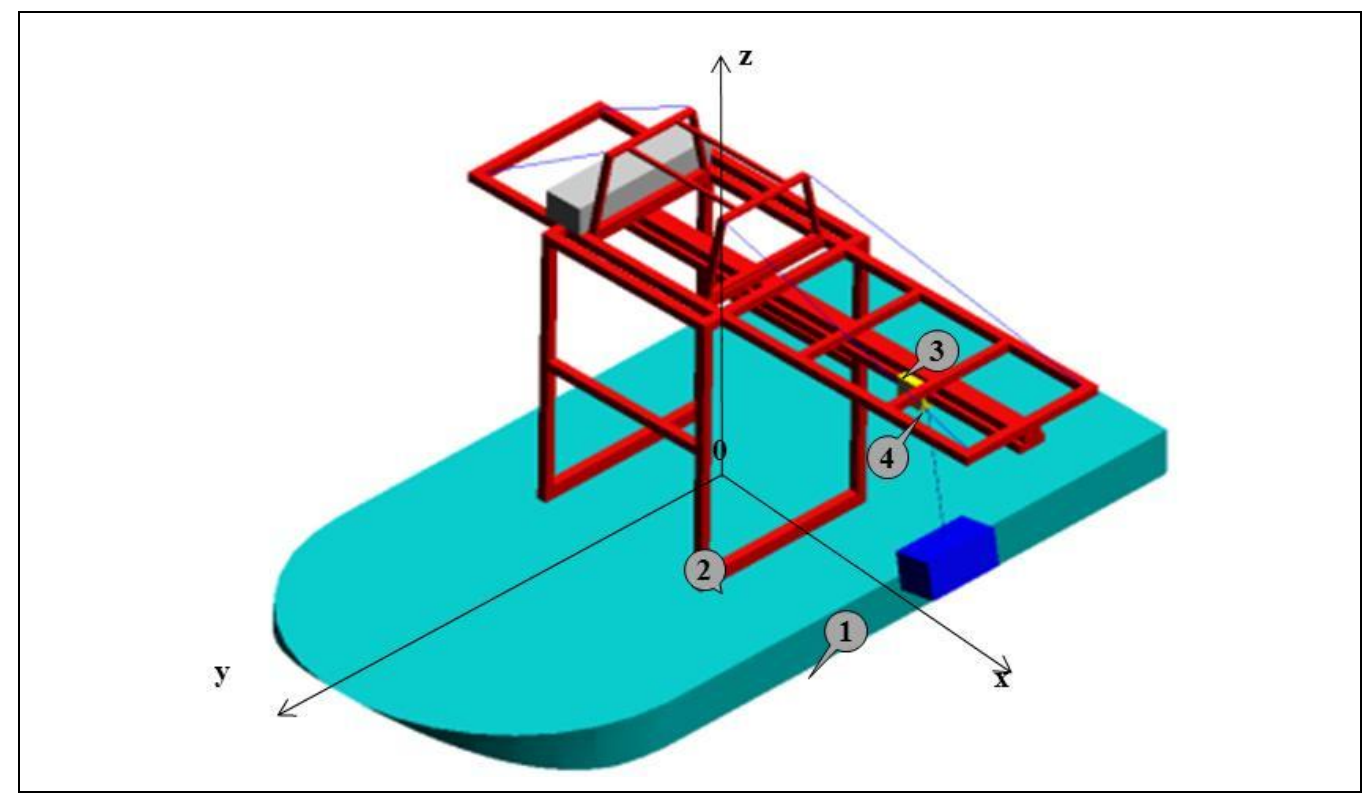

Fig.4. The ADAMS model of the mechanical MHC system

The center of floating base coordinate (denoted by 1) is fixed at the center of the Cartesian coordinate in the ADAMS environment using a revolute joint. The sway motion of floating base is created by a rotational joint motion based upon the wave disturbance function. The frame system (denoted by 2) is mounted on the floating base and moved along the floating base using a translation joint. The trolley (denoted by 3 ), which is driven by force that is generated from a motor, is slid on the frame along X-direction using a translation joint. The container (denoted by 4 ) is jointed to the trolley using a spherical joint, and it moved following the trolley motion. The virtual simulation in ADAMS environment is carried out to investigate the real dynamic behaviour of the virtual mechanical MHC prototype. Through simulation results, the designer can modify the mechanical design to achieve a desired mechanical system. 
In order to design a control system for controlling the virtual mechanical prototype of the MHC system, MATLAB software is a useful tool for this task. This software exchanges information with the ADAMS software. The exchange process creates a closed loop, which the outputs from the ADAMS model are the inputs for the control system and vice-versa. The measured parameter values from outputs of ADAMS model are necessary for control, and the signal output from the control system directly acts on the ADAMS model. The control solution and design method are presented in the detail in the next section.

\section{Developing a control system for the virtual mechanical MHC prototype}

Developing a control system for the virtual MHC model is essential for cosimulation of both separately simulations in a whole system. The control design is developed based on ADAMS/Control and MATAB/Simulink. The connection between ADAMS and MATLAB environments in the co-simulation model is shown in Fig.5. In order to export the virtual MHC model from ADAMS to MATLAB environment, firstly, the input and output variables are defined in the ADAMS model. The input of ADAMS model is a force signal that generates from the controller for controlling the trolley movement, and the outputs from ADAMS model are the measured parameters of the trolley movement and swing angle of load, respectively.

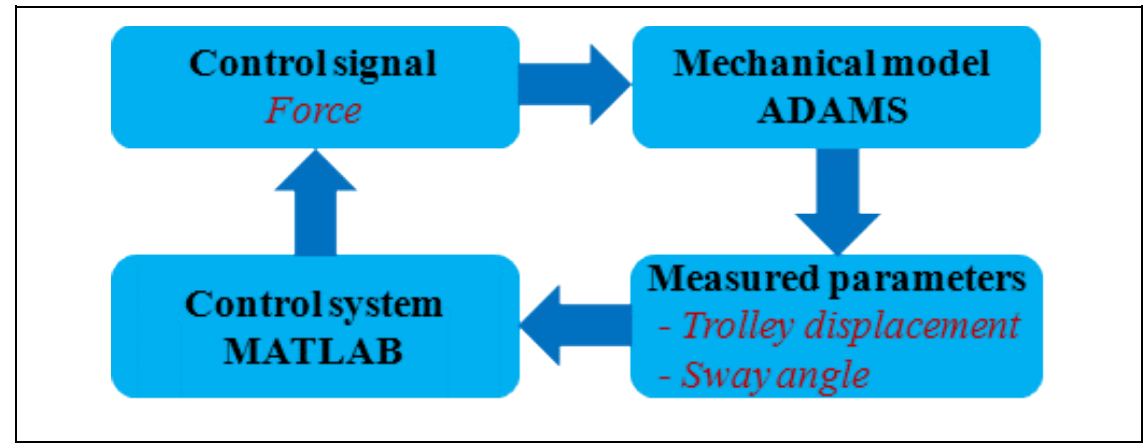

Fig.5. Connection between the ADAMS and MATLAB in the co-simulation model

Several controllers were applied for controlling the accuracy of the trolley position and suppress the swing angle of load such as Fuzzy, PID, Sliding mode controller, etc. The proportional-integral-derivative (PID) controller is widely used in many control applications because of its simplicity and effectiveness (Kuo et al., 2008). In the PID controller, three PID control gains $\left(K_{P}, K_{I}\right.$, and $\left.K_{D}\right)$ are usually fixed. The disadvantage of PID controller is poor capability of dealing with the unstable system that disturbance and parameter variations. Meanwhile, Sliding mode control (SMC) is known as a modern control method that uses state-space approach to analyse such as the system. Advantage of SMC is its robustness against system parameter variations and external disturbances.

Based on these advantages of PID and SMC controllers, this paper proposes an adaptive sliding mode PID controller (ASMP), which combines the advantages of both analyzed controllers. The way SMC deal with uncertainty is to drive the plants state trajectory onto a sliding surface and maintain the error trajectory on this surface for all subsequent times. The sliding surface is defined such that the state tracking error converges to zero with input reference (Kuo et al., 2008). An additional 
adaptive law is developed in such a way that the PID control gains can be updated online with an adequate adaptation mechanism that is adaptive with the variations of system parameters and external disturbances. The block diagram of the ASMP controller is shown in Fig.6.

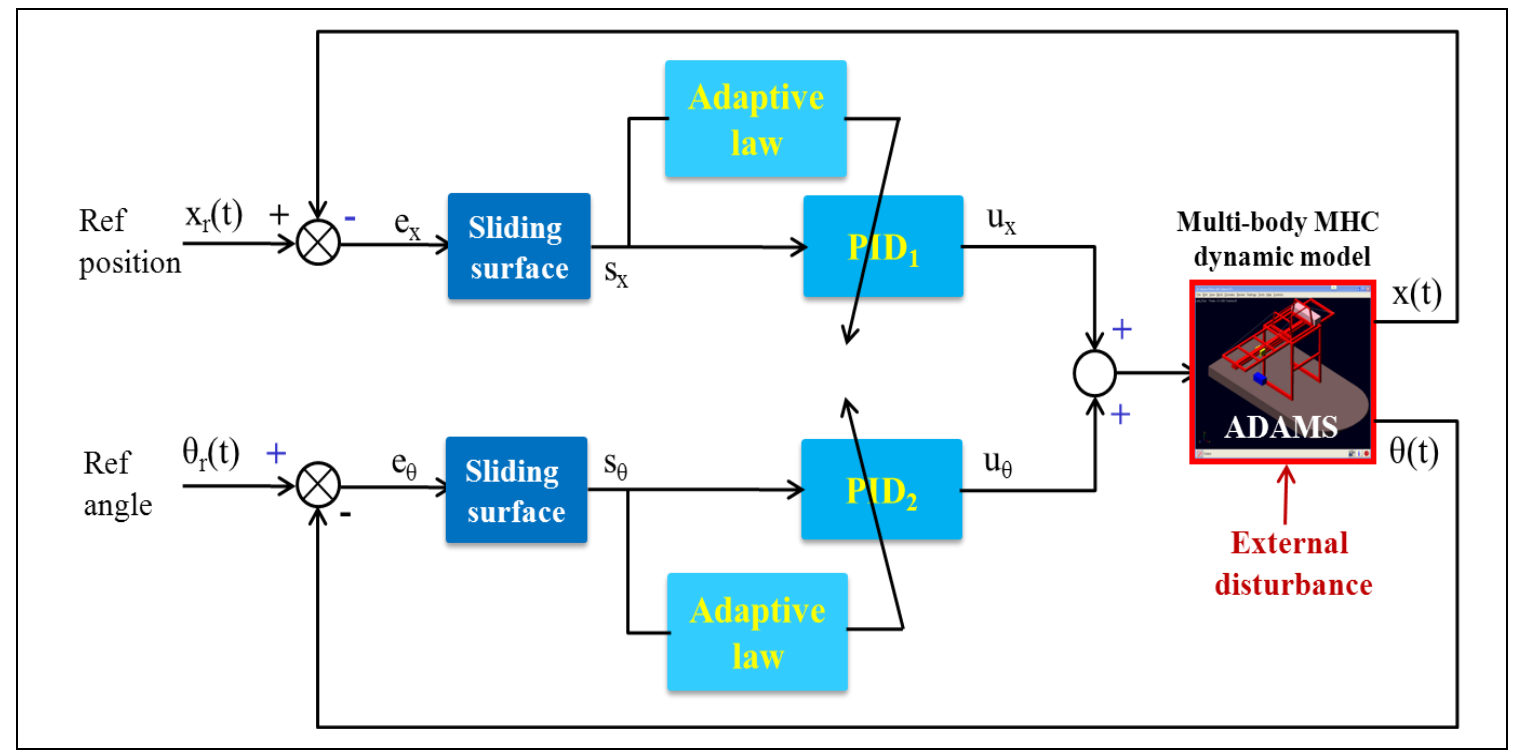

Fig.6. Block diagram of the ASMP controller

\section{Simulation results and conclusion}

The simulation is carried out in the virtual MHC model in consideration of the wave disturbance and system parameter variations. The sea wave disturbance is changed by the height and frequency. Meantime, the system parameters (load and stretch of rope) are changed by the length and mass. The parameter values for virtual simulation are given in the Table 1.

\begin{tabular}{|l|l|}
\hline \multicolumn{1}{|c|}{ Parameters } & \multicolumn{1}{c|}{ Values } \\
\hline Simulation time $(\mathrm{t})$ & $30 \mathrm{sec}$ \\
\hline The control objectives: & \\
- Reference trolley position $\left(\mathrm{X}_{\mathrm{d}}\right)$ & $2.0 \mathrm{~m}$ \\
- Reference sway angle of load $\left(\theta_{\mathrm{d}}\right)$ & $0 \mathrm{rad}$ \\
\hline Model parameters: & $3 \mathrm{~m}$ \\
- Crane height $(\mathrm{h})$ & $1.2 \mathrm{~m} ; 1.5 \mathrm{~m}$ \\
- Rope length $(\mathrm{l})$ & $127 \mathrm{~kg}$ \\
- Trolley mass $\left(\mathrm{m}_{\mathrm{t}}\right)$ & $148 \mathrm{~kg} ; 350 \mathrm{~kg}$ \\
- Load mass $\left(\mathrm{m}_{\mathrm{l}}\right)$ & \\
\hline Disturbance parameters: & $0.02 \mathrm{~m} ; 0.04 \mathrm{~m}$ \\
- Sea wave height $\left(\mathrm{h}_{\mathrm{w}}\right)$ & $1.5 \mathrm{rad} / \mathrm{sec} ; 3 \mathrm{rad} / \mathrm{sec}$ \\
\hline - Sea wave frequency $\left(\mathrm{f}_{\mathrm{w}}\right)$ & \\
\hline Control gains of the ASMP: & $\lambda=200, \gamma=1 e-15, b=1 / 127$ \\
\hline
\end{tabular}


- Tracking the desired angle

$$
\lambda=200, \gamma=-1 e-9, b=1
$$

Tab. 1 . The system parameter values for simulation

In order to evaluate the proposal ASMP controllers, which include control the accuracy of the trolley position and suppress the sway angle of load, are considered in the control criteria (Solihin et al. 2007):

For the position controller, the ASMP position controller is optimized by considering the desired specification:

- Overshoot $\leq 2 \%$

- Settling time $\leq 5 \mathrm{~s}$

- Steady state error $\leq \pm 15 \%$

On the other hand, the ASMP angle controller is optimized based on the desired specifications:

- Settling time $\leq 5 \mathrm{~s}$

- Residual swing $\leq \pm 0.05 \mathrm{rad}$

Figs.7, 8, 9, and 10 are shown the simulation results of the position trolley and swing angle responses based on the ASMP controllers. Table 2 is the comparison results on the position and angle performances under consideration of sea wave and system parameter variations.

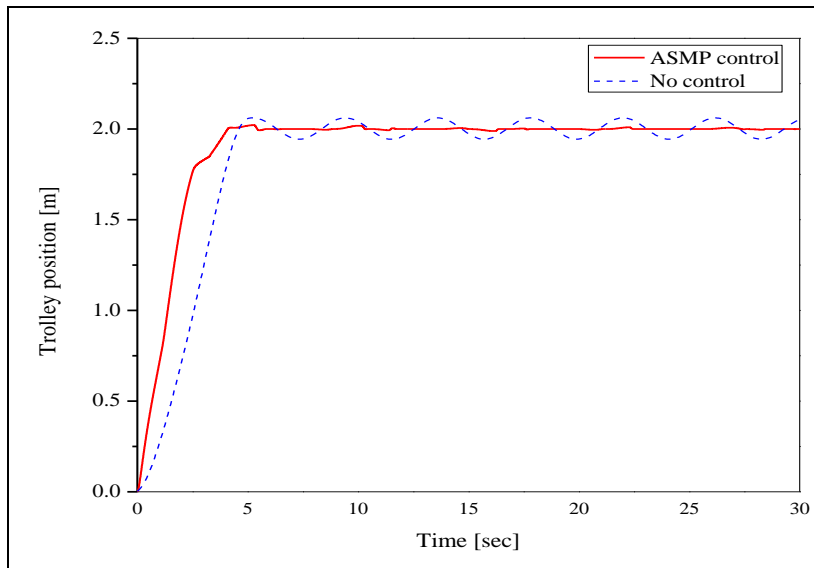

(a)

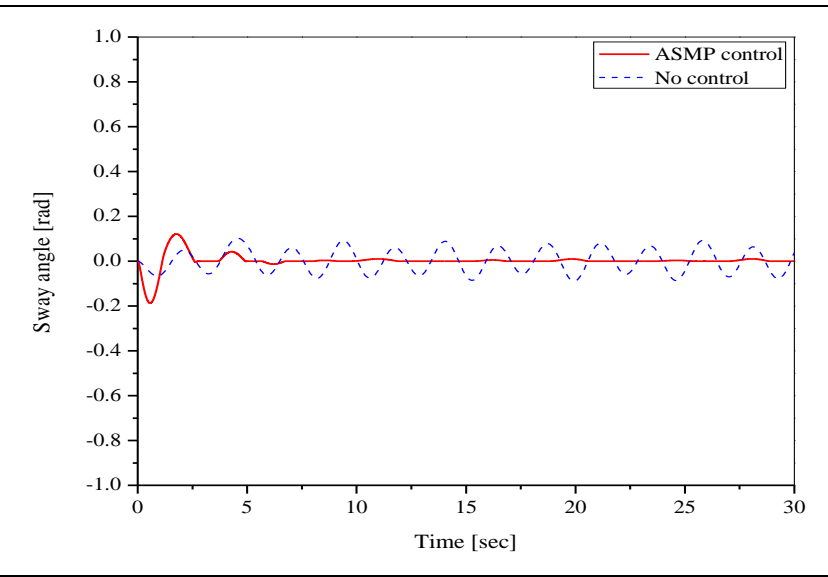

(b)

Fig. 7. The position and angle responses of ASMP control with $h_{w}=0.02 m$, $\mathrm{f}_{\mathrm{w}}=1.5 \mathrm{rad} / \mathrm{s}, 1=1.2 \mathrm{~m}, \mathrm{~m}_{\mathrm{l}}=148 \mathrm{~kg}$. (a) Trolley motion. (b) Sway motion

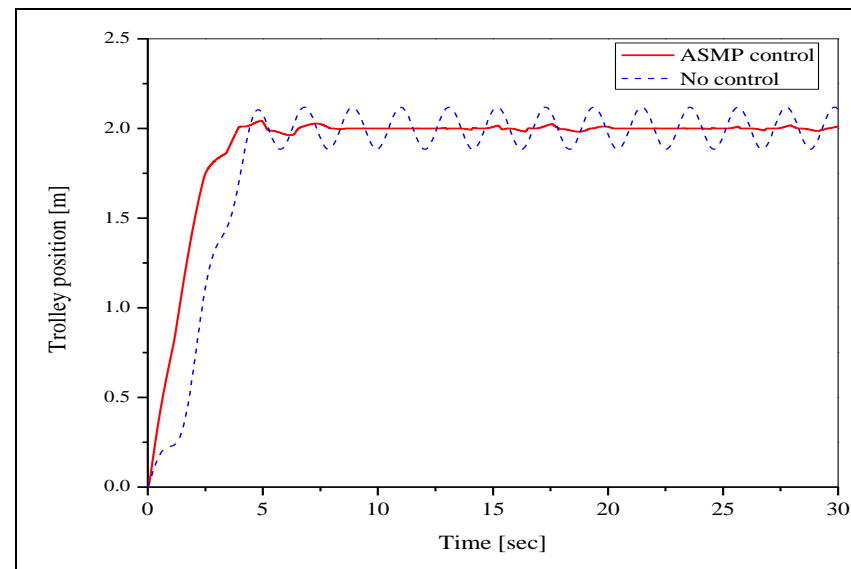

(a)

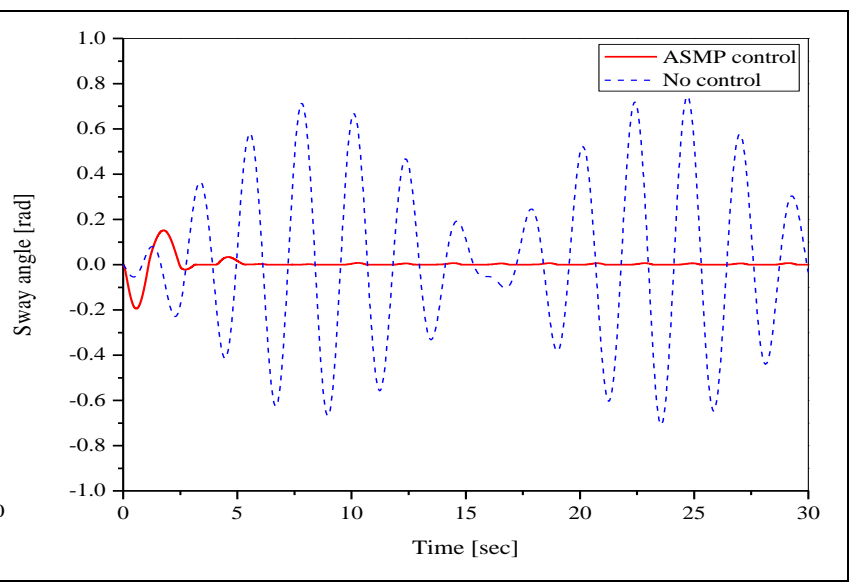

(b) 
Fig. 8. The position and angle responses of ASMP control with $\mathrm{h}_{\mathrm{w}}=0.04 \mathrm{~m}, \mathrm{f}_{\mathrm{w}}=3 \mathrm{rad} / \mathrm{s}$, $1=1.2 \mathrm{~m}, \mathrm{~m}_{\mathrm{l}}=148 \mathrm{~kg}$. (a) Trolley motion. (b) Sway motion

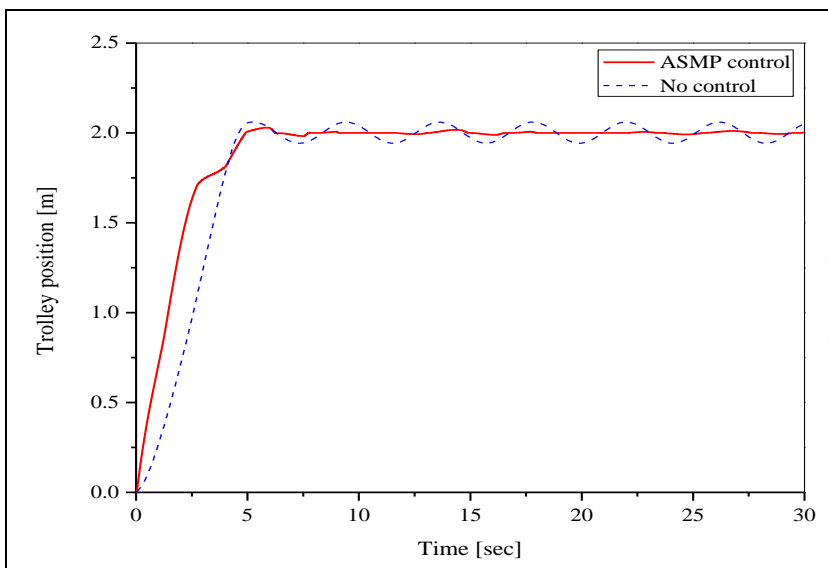

(a)

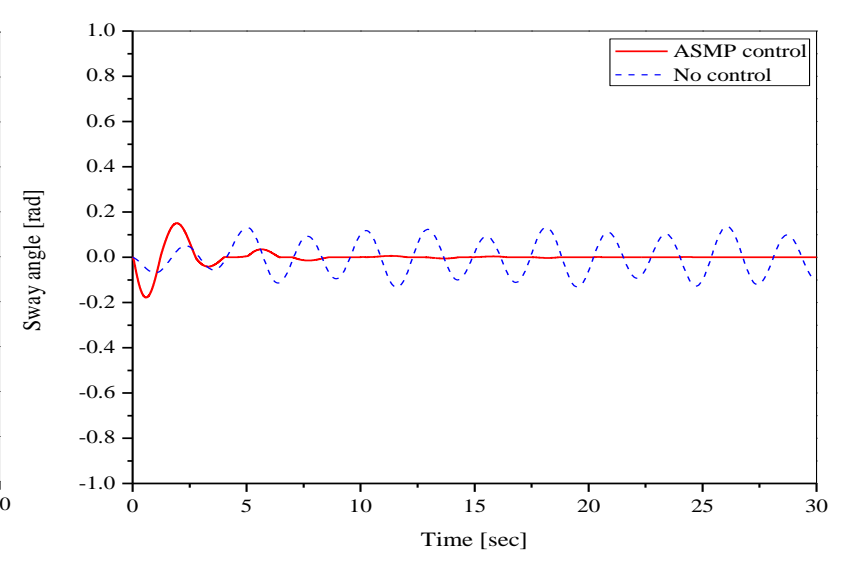

(b)

Fig. 9. The position and angle responses of ASMP control with $h_{w}=0.02 m$, $\mathrm{f}_{\mathrm{w}}=1.5 \mathrm{rad} / \mathrm{s}, \mathrm{l}=1.5 \mathrm{~m}, \mathrm{~m}_{\mathrm{l}}=350 \mathrm{~kg}$. (a) Trolley motion. (b) Sway motion

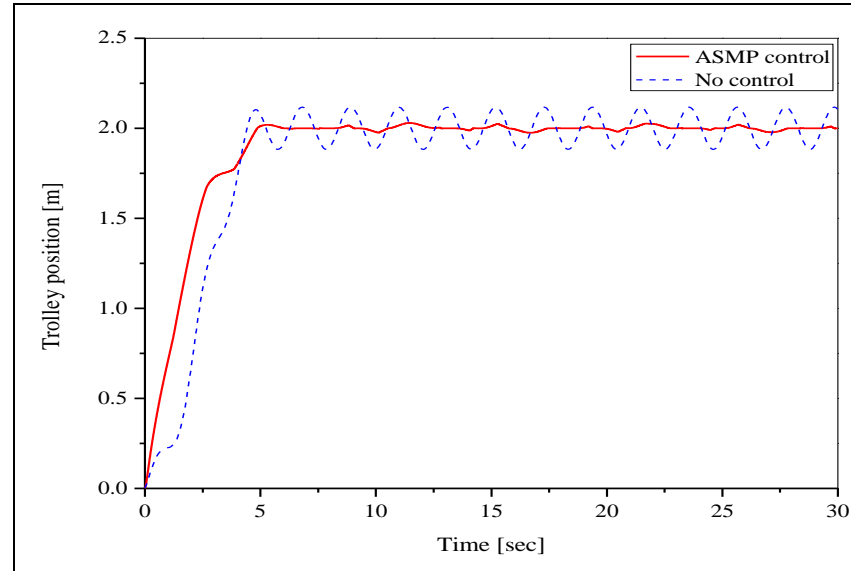

(a)

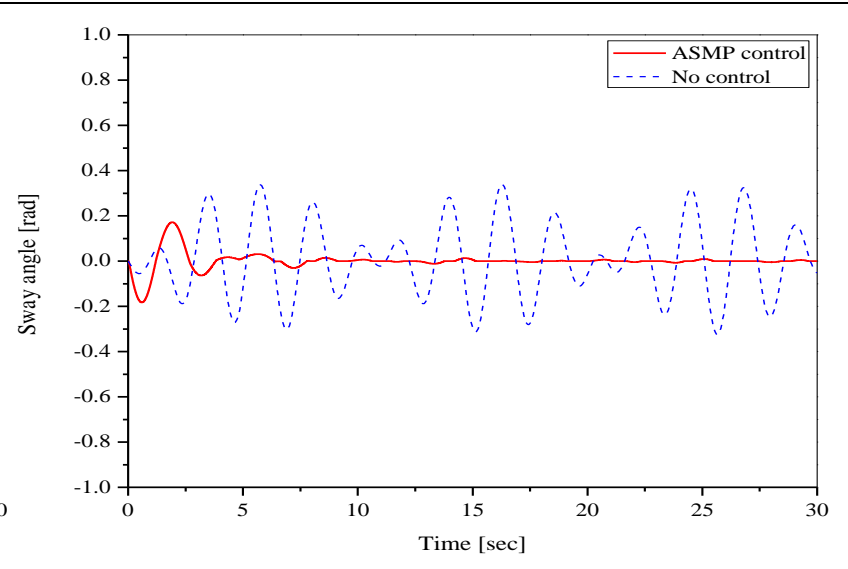

(b)

Fig. 10. The position and angle responses of ASMP control with $h_{w}=0.04 m$, $\mathrm{f}_{\mathrm{w}}=3 \mathrm{rad} / \mathrm{s}, \mathrm{l}=1.5 \mathrm{~m}, \mathrm{~m}_{\mathrm{l}}=350 \mathrm{~kg}$. (a) Trolley motion. (b) Sway motion

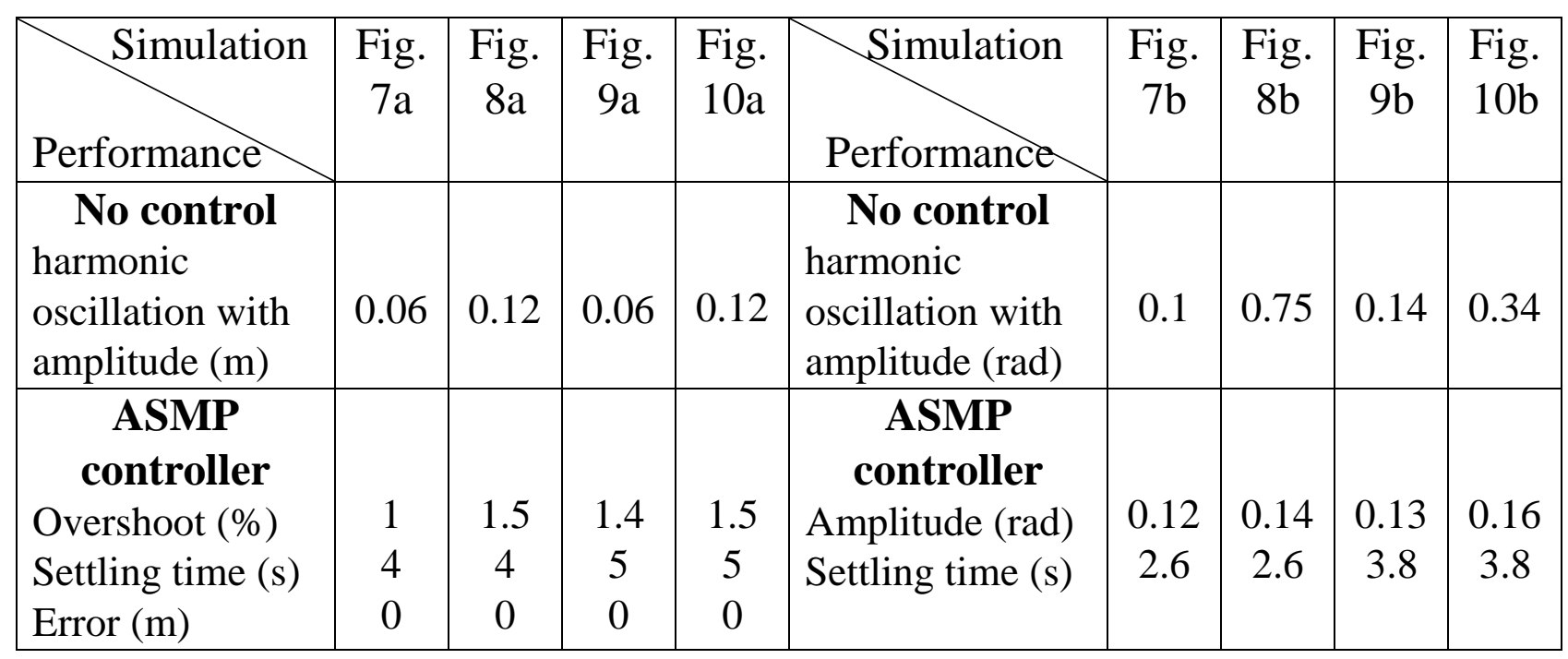

Tab. 2. Comparison of positioning and swing angle performances 
Based on evaluating the comparison results through the position and angle performances in Table 2. The performances are satisfied the mentioned control criteria. The overshoot appears less than $2 \%$, settling time maintains in range 45 seconds, and steady-state error approximately zero. The position response is tracking the desired position, and the sway motion of load is perfectly eliminated. Through analyzed above, it can be concluded that the developed ASMP control method can be used effectively for controlling the accuracy of the trolley position and suppress the swing angle of load in the MHC case. However, the study restriction has lacked the experimental results in the physical model (testbed). Due to the testbed has been being manufactured and tested in University of Ulsan. Hence, in the early stage, an experiment was done to verify the dynamic behaviour of the MHC on the virtual prototype and physical models in good agreement. The experiment result showed that the virtual prototype model can be used to imitate the real mechanical model.

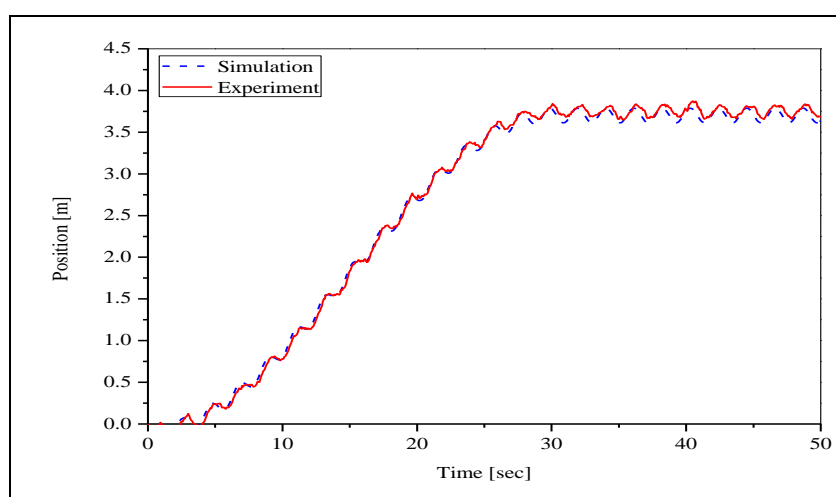

(a)

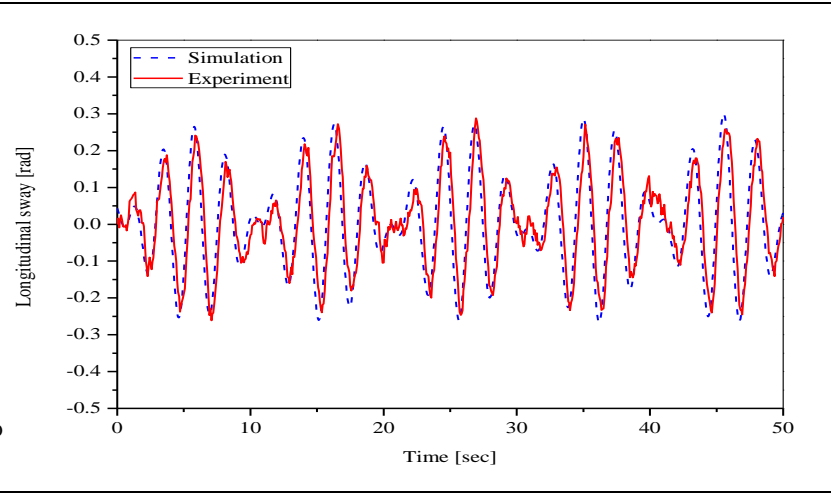

(b)

Fig. 11. Comparison between the simulation and experiment performances of the trolley displacement and swing angle of the load in the case of sea wave height: $\mathrm{h}_{\mathrm{w}}=0.03 \mathrm{~m}$ and frequency: $\mathrm{f}_{\mathrm{w}}=3 \mathrm{rad} / \mathrm{sec}$; Rope length: $1=1.5 \mathrm{~m}$; Container mass: $\mathrm{m}=350 \mathrm{~kg}$. (a) Trolley displacement. (b) Longitudinal sway of payload.

In this article, the virtual simulation of the real behaviour was presented here, and the co-simulation model with the proposed ASMP control approach was also established in the virtual prototype model. The virtual simulation results show that the ASMP control strategy is robust with disturbance, and this virtual prototype approach can be used to replace for the traditional build-and-test approach. The proposed ASMP control approach will be validated in the real MHC model of University of Ulsan in the second stage of research, and the implementation results will present in the future paper.

\section{Acknowledgements}

This research was supported by the Ministry of Knowledge Economy (MKE), under the Industrial Source Technology Development Programs supervised by the Korea Evaluation Institute of Industrial Technology (KEIT). 
Park, H. S. \& Le, N. T.: A 3D Virtual Simulation System for Mobile Harbour Crane

\section{References}

Alexandru, C. \& Pozna, C. (2009). Dynamic modeling and control of the windshield wiper mechanisms. Journal WSEAS transactions on systems, vol. 8, no. 7, pp. 825-834

Fang, Y.; Dixon, W. E.; Dawson, D. M. \& Zergeroglu, E. (2003). Nonlinear coupling control laws for an underactuated overhead crane system. Mechatronics, IEEE/ASME Transactions on, vol. 8, no. 3, pp. 418-423

Hong, K. T.; Huh, C. D. \& Hong, K. S. (2003). Command Shaping Control for Limiting the Transient Sway Angle of Crane System. International Journal of Control, Automation, and System, vol. 1, no. 1, pp. 43-53

Kawai, H.; Kim, Y. B. \& Choi, Y. W. (2009). Anti-sway system with image sensor for container cranes, J. Mech. Sci. Technol., vol. 23, no. 10, pp. 2757-2765

Kim, Y. S.; Seo, H. S. \& Sul, S. K. (2001). A new anti-sway control scheme for trolley crane system. Industry applications conference of Thirty-sixth IAS Annual Meeting, vol. 1, no. 1, pp. 548-552, Korea

Kim, Y. S.; Yoshihara, H.; Fujioka, N.; Kasahara, H.; Shim, H. \& Sul, S. K. (2003). A new vision-sensorless anti-sway control system for container cranes. Industry Applications conference of 38th IAS Annual Meeting, vol. 1, pp. 262269

Kuo, T. C.; Huang, Y. J.; Chen, C. Y. \& Chang, C. H. (2008). Adaptive sliding mode control with PID tuning for uncertain systems. Engineering letters, 16:3, EL_16_3_06.

Ngo, Q. H.; Hong, K. S.; Kim, K. H.; Shin, Y. J. and Choi, S. H. (2008). Skew control of a container crane. International conference on control, automation and systems, pp. 1490-1494

Park, H.; Chwa, D. \& Hong, K.-S. (2007). A feedback linearization control of container cranes: Varying rope length. Int. J. Control Autom. Syst., vol. 5, no. 4, pp. 379-387

Park, K. R. \& Kwon, D. S. (2010). Swing-free control of mobile harbour crane with accelerometer feedback. International Conference on Control, Automation and Systems 2010, pp. 1322-1327

Spanos, P. T. D. (1996). Filter approaches to wave kinematics approximations. Journal of Applied Ocean Research, vol. 8, no. 1, pp. 2-7

Yoshida, Y. \& Tabata, H. (2008). Visual feedback control of an overhead crane and its combination with time-optimal control. Advanced Intelligent Mechatronics, 2008. IEEE/ASME International Conference, pp. 1114-1119 